\begin{tabular}{|c|c|}
\hline Title & Controlled morphology of aluminum alloy nanopillar films: from nanohorns to nanoplates \\
\hline Author(s) & Fujii, Takashi; A oki, Y oshitaka; Fushimi, Koji; Makino, Takeshi; Ono, Shoji; Habazaki, Hiroki \\
\hline Citation & $\begin{array}{l}\text { Nanotechnology, 21(39), 395302 } \\
\text { https://doi.org/10.1088/0957-4484/21/39/395302 }\end{array}$ \\
\hline Issue Date & 2010-10-01 \\
\hline Doc URL & http:/hdl.handle.net/2115/43936 \\
\hline Rights & $\begin{array}{l}\text { This is an author-created, un-copyedited version of an article accepted for publication in Nanotechnology. IOP } \\
\text { Publishing Ltd is not responsible for any errors or omissions in this version of the manuscript or any version derived } \\
\text { from it. The definitive publisher authenticated version is avail able online at } 10.1088 / 0957-4484 / 21 / 39 / 395302\end{array}$ \\
\hline Type & article (author version) \\
\hline File Information & Nan21-39_395302.pdf \\
\hline
\end{tabular}

Instructions for use 


\title{
Controlled morphology of aluminum alloy nanopillar films: from nanohorns to nanoplates
}

Short title: Aluminum alloy nanopillar films

Takashi Fujii ${ }^{1}$, Yoshitaka Aoki ${ }^{1}$, Koji Fushimi ${ }^{1}$, Takeshi Makino ${ }^{2}$, Shoji Ono ${ }^{2}$ and Hiroki Habazaki ${ }^{1}$

${ }^{1}$ Division of Materials Chemistry, Faculty of Engineering, Hokkaido University, N13 W8, Kita-ku, Sapporo 060-8628, Japan

${ }^{2}$ Nippon Chemi-Con Corporation, 363, Arakawa, Takahagi 318-8505, Japan

E-mail: habazaki@eng.hokudai.ac.jp

\begin{abstract}
Nanopillar films of Al-Nb alloys have been fabricated on substrates with a regular concave cell structure by oblique angle physical vapor deposition. The concave cell structure of substrate increases the shadow region for the flux of depositing atoms, assisting the formation of an isolated nanopillar on each cell. Depending upon the alloy composition and deposition angle, the pillar shape changes from horn-like nanopillars through triangle nanoprisms to nanoplates. The Al-Nb alloy nanoplate films with wide gaps between plates are of interest as an electrode for capacitor application. The dielectric oxide film formed on the nanoplate film showed the capacitance more than 10 times larger than that on the respective flat film, due to enlarged surface area.
\end{abstract}

Keywords; nanopillar film, oblique angle deposition, Al-Nb alloys, anodic oxide, capacitor

Subject classification numbers: 68.55.-a, 81.15.-z, 81.15.Cd, 82.45.Cc, 84.32.Tt

Submitted to: Nanotechnology 


\section{Introduction}

Porous materials have potential widespread applications in various fields, such as capacitors, sensors, catalyst supports, magnetic storage media, field emitters, photonic crystals and water/oil repellent surfaces [1, 2]. Oblique angle deposition (OAD) in physical vapor deposition (PVD) is one of the useful and attractive techniques to fabricate porous films with tilted isolated columnar structure [3]. The porosity is generated due to self-shadowing effect and limited surface diffusion of adatoms. Recently, it has been reported that controlled rotation of substrate during $\mathrm{OAD}$ enables to create sculptured micro- and nano-structured thin films, such as nanopillars [4-9], zig-zag [10-13], nanospirals [14, 15] and Y-shape [16] columns. This advanced technique, often referred to as glancing angle deposition, allows us to develop a range of engineered micro- and nano-structures [1, 3].

Aluminum electrolytic capacitor is widely used in electronic industry. Highly porous aluminum metal electrodes, produced by electrochemical etching processes in strong acid solutions, are used to enhance the capacitance. However, due to increasing environmental regulation, dry processes, such as PVD and chemical vapor deposition (CVD), have attracted increasing attention in capacitor industry as an environmentally friendly alternative of wet electrochemical process. In addition, the coating of aluminum surface with other metal or alloys by PVD increases the chemical stability. So, more reliable capacitors can be made. Oblique angle deposition is a promising PVD process to develop porous nanopillar films with high surface area.

Since the permittivity of dielectric alumina films formed by anodizing of aluminum is only $~ 10$, there is an increased interest to form composite oxide films with higher permittivity on aluminum. Two-step process of sol-gel or MOCVD coatings of $\mathrm{Nb}_{2} \mathrm{O}_{5}, \mathrm{Ta}_{2} \mathrm{O}_{5}, \mathrm{ZrO}_{2}$ and $\mathrm{SiO}_{2}$ and subsequent anodizing, have been used to form composite oxide films with increased capacitance [17-21]. The formation of $\mathrm{Nb}_{2} \mathrm{O}_{5} / \mathrm{Al}_{2} \mathrm{O}_{3}$ composite oxide films is particularly effective in enhancing capacitance [22], while the $\mathrm{SiO}_{2} / \mathrm{Al}_{2} \mathrm{O}_{3}$ composite oxide films increase the breakdown voltage [17]. The capacitance enhancement can be also achieved by incorporating foreign species from alloy substrate. For capacitor application, enlargement of surface area of the alloy electrode is also necessary to increase the capacitance.

In this study, an attempt has been made to fabricate porous aluminum alloy films with isolated nanopillar structure by magnetron sputtering for potential electrolytic capacitor application. To form such porous films, oblique angle deposition has been utilized on textured substrate with a regular concave cell structure. Niobium has been added as an alloying element, since anodic niobium oxide has high permittivity of $\sim 42$. We also presume that the addition of a refractory metal, such as niobium, to aluminum reduces the high surface diffusivity of aluminum adatoms during deposition, which impedes the formation of isolated columnar films. 
Textured substrate has been introduced to control the size of nanogaps between nanopillars. Controlling of the nanogaps is essential for capacitor application, since the formation of a dielectric oxide film on the metallic nanopillars by anodizing results in the volume expansion. The nanogaps must be present even after the formation of oxide to keep the high surface area and high capacitance. For the fabrication of the textured substrate, we have used self-organized nanoporous anodic alumina formation on aluminum metal [23, 24]. The formation of such oxide film changes the metal/film interface from flat to hexagonally arranged cell structure. The metal surface with the concave cell structure is readily available as substrate after dissolution of the nanoporous alumina film. Here, we demonstrate the useful application of the textured substrate with regular concave cell structure to control the nanogaps between nanopillars. In addition, through the examination of the influences of deposition angle and alloy composition, we have fabricated nanohorn, triangle nanopillar and nanoplate films on the textured substrate, depending upon the deposition condition. Such controlled morphology of deposits should be realized by alloying with niobium, since it has been reported that fabrication of controlled aluminum nanostructures by PVD is difficult due to high surface diffusivity and associated facet formation [25].

\section{Experimental}

Al-Nb alloy films containing 20 to 53 at\% niobium, as well as high-purity aluminum films, were deposited by DC magnetron sputtering. Targets for alloy preparation consisted of a 99.999\% purity aluminum disk of $100 \mathrm{~mm}$ in diameter and 99.9\% purity niobium disks of 20 $\mathrm{mm}$ in diameter, with the latter placed symmetrically on an erosion region of the former disk. The niobium concentrations of the deposited films were controlled by changing the number of niobium disks. The chamber was first evacuated to less than $5 \times 10^{-5} \mathrm{~Pa}$ and then high-purity argon gas was introduced into the chamber. During sputtering, the argon pressure was maintained at 0.3-0.4 Pa at a constant current of 0.5 A. The deposition times were 1.8, 3.6 and $5.4 \mathrm{ks}$. The films were deposited on flat glass and textured aluminum substrates. Using tilted substrate holders, Al-Nb alloy films were deposited at deposition angles of $0^{\circ}, 70^{\circ}, 85^{\circ}$ and $110^{\circ}$ with respect to the substrate normal. In order to deposit alloy films of uniform composition, substrate holders were rotated around the central axis of the chamber as well as their own axis. Thus, the sputtering rate was approximately one fifth that without substrate rotation.

The textured aluminum substrate was prepared by anodizing $99.99 \%$ pure aluminum sheet in $0.3 \mathrm{~mol} \mathrm{dm}^{-3}$ oxalic acid at a constant voltage of $40 \mathrm{~V}$ at $298 \mathrm{~K}$ for $1.2 \mathrm{ks}$ or $0.1 \mathrm{~mol}$ $\mathrm{dm}^{-3}$ phosphoric acid solution at a constant current density of $100 \mathrm{~A} \mathrm{~m}^{-2}$ (steady state formation voltage of $\sim 160 \mathrm{~V}$ ) at $293 \mathrm{~K}$ for $1.8 \mathrm{ks}$, and then the anodic oxide films formed were dissolved by immersing the anodized specimen in a mixture of chromic acid and phosphoric acid at $343 \mathrm{~K}$. 
During anodizing, self-ordered nanoporous alumina films with hexagonal cell structure was developed. The cell size increases almost linearly with formation voltage [26, 27]. The resultant surfaces have a cellular morphology as shown in Fig. 1. The cell sizes prepared in oxalic and phosphoric acids were $70-80 \mathrm{~nm}$ and $300-400 \mathrm{~nm}$, respectively. In these concave cellular structures, the cell boundary is ridge, appearing as white lines in Fig. 1. The height difference between the center of a cell (bottom) and triple point of cell boundary (peak top) was $\sim 50 \mathrm{~nm}$ and $200 \mathrm{~nm}$ for the substrates formed in oxalic acid and phosphoric acid, respectively.
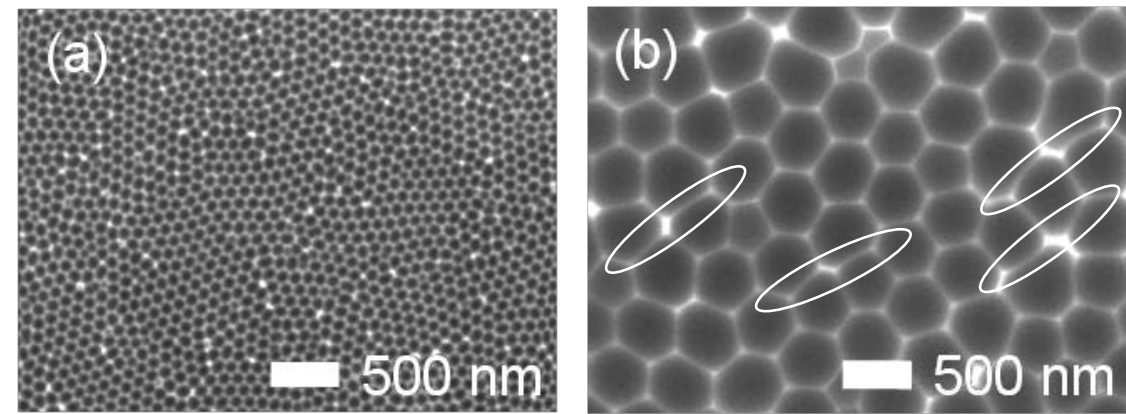

Figure 1 Substrate surface morphologies with a hexagonal concave cell structure. The cell sizes prepared in oxalic and phosphoric acids are (a) 70-80 nm and (b) 300-400 nm, respectively. The regions where cell boundaries of two or three cells are almost in line are indicated by ellipses in (b).

Surfaces and cross-sections of the deposited films were observed by a JEOL, JSM-6500F field emission scanning electron microscope (SEM) with EDS facilities. The EDS was used to estimate the deposited alloy compositions (Table 1).

Table 1 The compositions of Al-Nb alloy films deposited at different angles using composite targets with 4 and 6 niobium disks.

\begin{tabular}{ccccc}
\hline \multirow{2}{*}{ Number of Nb disks } & \multicolumn{5}{c}{ Nb content (at\%) at each deposition angle } \\
\cline { 2 - 5 } & $0^{\circ}$ & $70^{\circ}$ & $85^{\circ}$ & $110^{\circ}$ \\
\hline 4 & 27 & 21 & 20 & 13 \\
6 & 53 & 47 & 43 & 36 \\
\hline
\end{tabular}

The structures of the deposits were identified by grazing incidence X-ray diffraction (XRD) using $\mathrm{Cu} \mathrm{K} \alpha$ radiation under an incident angle of $2^{\circ}$. Rigaku, RINT-2000 system was used to obtain the XRD patterns. The porosity of the deposits was evaluated from voltage-time responses of the specimens during anodizing at a constant current density of $10 \mathrm{~A} \mathrm{~m}^{-2}$ in $0.1 \mathrm{~mol}$ $\mathrm{dm}^{-3}$ ammonium pentaborate electrolyte at $293 \mathrm{~K}$. The current density was set relative to the 
apparent geometrical surface area. Thus, the rate of voltage increase was reduced as the surface area increased. In addition, the capacitance of some specimens was measured by electrochemical impedance spectroscopy (EIS) in $0.1 \mathrm{~mol} \mathrm{dm}^{-3}$ ammonium pentaborate electrolyte at $293 \mathrm{~K}$ after anodizing at selected voltages for $600 \mathrm{~s}$ in the same electrolyte. EIS data were obtained in the frequency range of $10^{-1}-10^{5} \mathrm{~Hz}$ using a Solartron 1255B frequency response analyzer.

\section{Results and Discussion}

\subsection{Influence of cell size of textured substrate}

Figure 2 shows SEM images of surfaces and cross-sections of the $\mathrm{Al}-21$ at\% $\mathrm{Nb}$ alloy films magnetron-sputtered on flat glass and textured aluminum substrates with different cell sizes at an oblique angle of $70^{\circ}$ for $1.8 \mathrm{ks}$. Tilted columnar structure is obvious for all the three deposits with the tilted column angle of $\sim 40^{\circ}$, which is smaller than the deposition angle of $70^{\circ}$, as is well known in oblique angle deposition [28]. Apparently, there are no gaps between neighboring columns for the deposits on the flat glass substrate and on the textured aluminum substrate with a cell size of 70-80 $\mathrm{nm}$. The gaps are developed only when the film is deposited on the aluminum substrate with a large cell size of 300-400 $\mathrm{nm}$. The ridge-to-ridge distance and the height difference between a ridge and a bottom of concave cell on the textured substrates increase as the cell size increases, enhancing self-shadowing effect. Thus, the isolated pillar film with open pores develops on the substrate with the large concave cell structure. The each pillar has a nanohorn-like morphology.
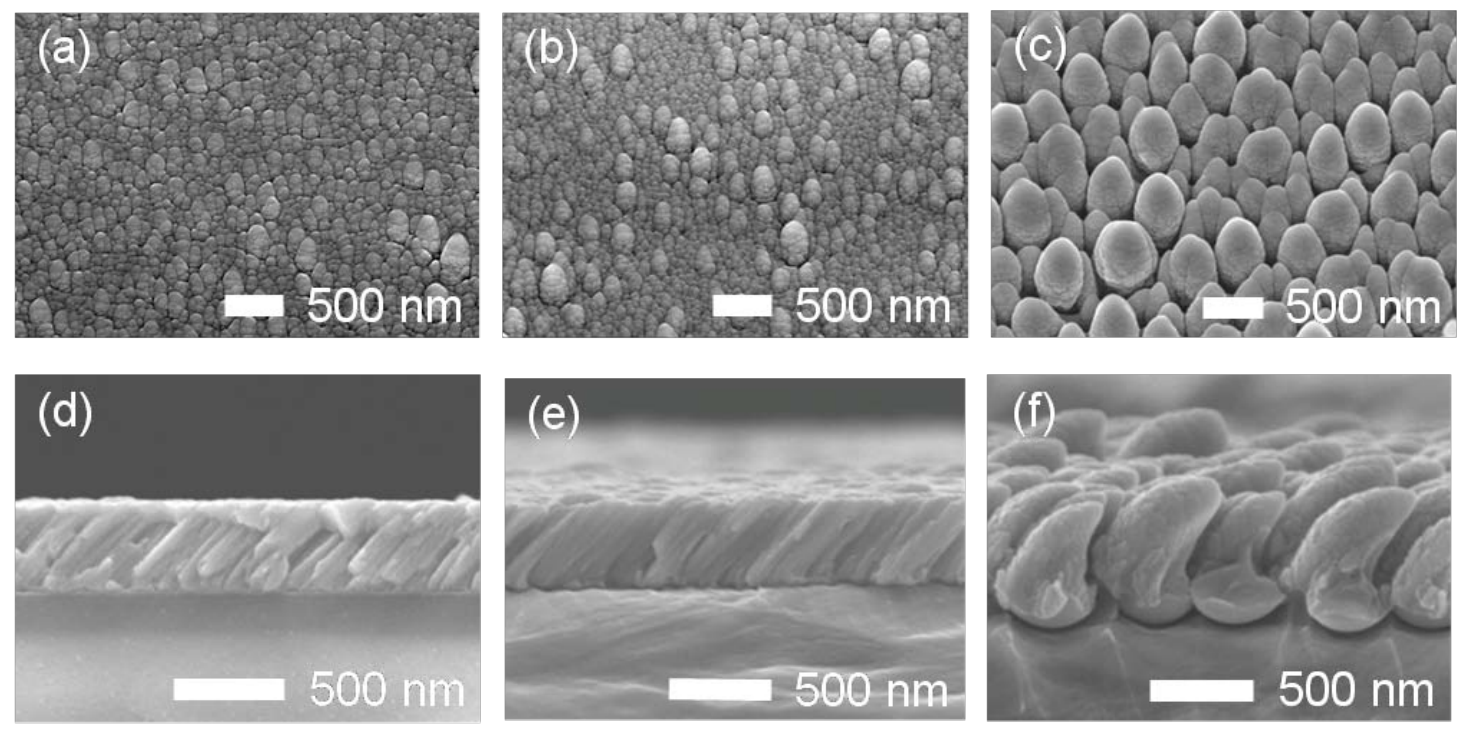

Figure 2 Surface and cross-sectional scanning electron micrographs of Al-21 at\% $\mathrm{Nb}$ alloy 
films deposited on flat glass (a, d) and textured aluminum substrates with different cell sizes of (b, e) 70-80 nm and (c, f) 300-400 nm at an oblique angle of $70^{\circ}$ for $1.8 \mathrm{ks}$.

The increased surface area due to open pore structure has been evaluated from the voltage-time response during anodizing at a constant current density of $10 \mathrm{~A} \mathrm{~m}^{-2}$ in $0.1 \mathrm{~mol} \mathrm{dm}^{-3}$ ammonium pentaborate electrolyte at $293 \mathrm{~K}$. In this condition, the anodic film growth on the Al-Nb alloys proceeds at high current efficiency close to 100\% [29]. The cell voltage increases linearly with anodizing time as a consequence of thickening of anodic oxide film at a constant rate during anodizing. For the flat $\mathrm{Al}-27 \mathrm{at} \% \mathrm{Nb}$ alloy deposited at $0^{\circ}$ on flat glass substrate, the voltage increases linearly with anodizing time with a slope of $0.36 \mathrm{~V} \mathrm{~s}^{-1}$ (Fig. 3). Similar slope is also obtained for the Al-21 at\% $\mathrm{Nb}$ alloy films deposited at $70^{\circ}$ on the flat and the textured (cell size: 70-80 nm) substrates, while markedly reduced slope is obvious for the film deposited on the textured (cell size: 300-400 nm) substrate. The reduced slope is associated with the increased surface area, since the real current density becomes lower than $10 \mathrm{~A} \mathrm{~m}^{-2}$ for the porous film. No significant change in the slope for the film deposited on the textured (cell size: 70-80 nm) substrate discloses that there are no open pores (gaps between columns) in the deposited film. The use of the textured substrate with large cell structure is of crucial importance to deposit isolated nanopillar films with increased surface area.

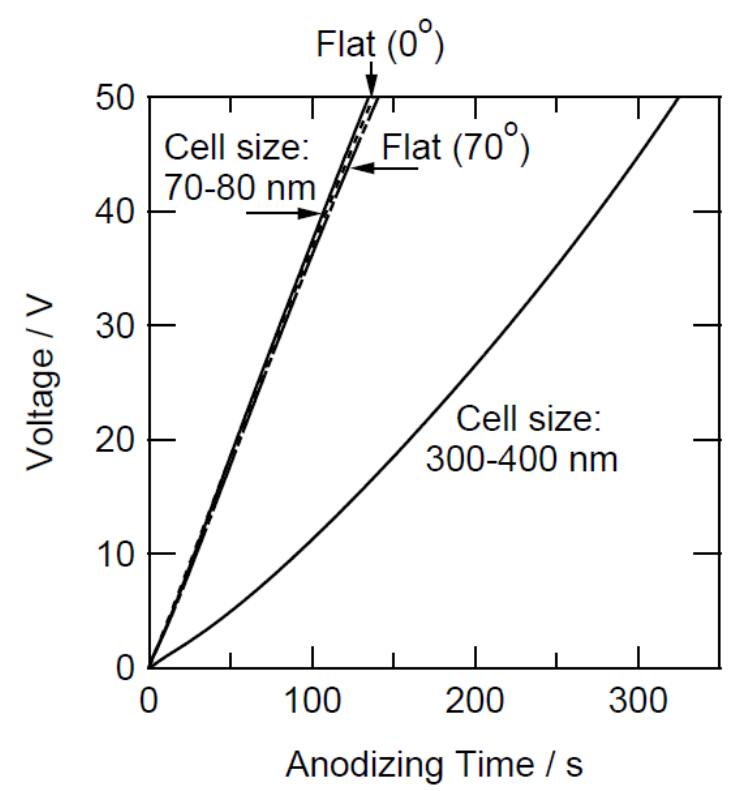

Figure 3 Voltage-time responses of $\mathrm{Al}-21$ at\% $\mathrm{Nb}$ alloy films deposited on flat glass and textured substrates with cell sizes of 70-80 $\mathrm{nm}$ and 300-400 $\mathrm{nm}$ at an oblique angle of $70^{\circ}$. The response of flat $\mathrm{Al}-27 \mathrm{at} \% \mathrm{Nb}$ alloy film deposited at $0^{\circ}$ is also shown for comparison. 


\subsection{Influence of alloy composition}

Interesting composition-dependent column morphology is evolved by oblique angle deposition on the textured aluminum substrate with a cell size of 300-400 nm. Figure 4 shows surfaces and cross-sections of aluminum and $\mathrm{Al}-(20$ and 43$)$ at\% $\mathrm{Nb}$ films deposited at $85^{\circ}$ on the textured substrates for $3.6 \mathrm{ks}$. The surface SEM images were taken from the columnar growth direction. The nanohorns of the Al-20 at\% Nb alloy film (Figs. 4(b) and 4(e)) changes to triangle nanoprisms and square pillars with a trapezoid plane by increasing the niobium content to 43 at\% (Fig. 4(c)). The characteristic feature of the Al-43 at\% Nb film is that the width of the pillars does not change to the pillar growth direction. In contrast, the horns (Al-20 at\% Nb) become thicker as the distance from substrate increases. When the deposition time of the Al-20 at\% $\mathrm{Nb}$ alloy film increased further to $5.4 \mathrm{ks}$, the neighboring nanohorns were connected each other and hence, there are almost no gaps between nanohorns. The width of the triangle nanoprisms and square pillars with a trapezoid plane was nearly constant even if the deposition time increased to 5.4 ks. The high-purity aluminum film (Figs. 4(a) and 4(d)), deposited for comparison, has columns with faceted surfaces. Facets are found only for the aluminum film and should be formed as a consequence of sufficient surface diffusion of aluminum adatoms to stable surface sites.
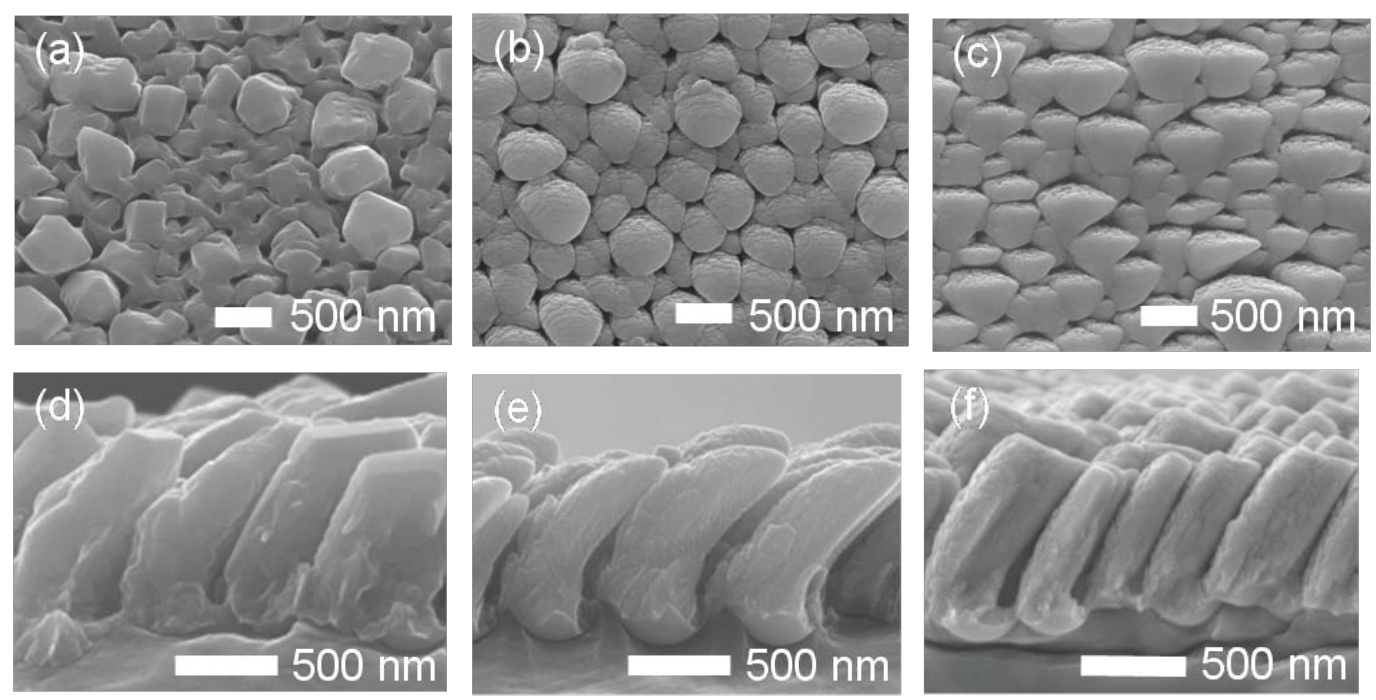

Figure 4 Surface and cross-sectional SEM images of (a, d) aluminum, (b, e) Al-20 at\% Nb and (c, f) $\mathrm{Al}-43 \mathrm{at} \% \mathrm{Nb}$ films deposited at $85^{\circ}$ on textured substrates for $3.6 \mathrm{ks}$.

Figure 5 shows $\mathrm{XRD}$ patterns of aluminum, $\mathrm{Al}-27 \mathrm{at} \% \mathrm{Nb}$ and $\mathrm{Al}-53$ at\% $\mathrm{Nb}$ films deposited at $0^{\circ}$ on glass substrate. The aluminum film shows a crystalline fcc pattern, while the two Al-Nb films reveal a halo, typical of amorphous structure. Even for the Al-Nb films 
deposited at oblique angles on the textured substrate, similar XRD patterns, except for the presence of fcc pattern from the aluminum substrate, were obtained. Thus, no influences of substrate material and texture on the crystalline structure of deposits were confirmed.

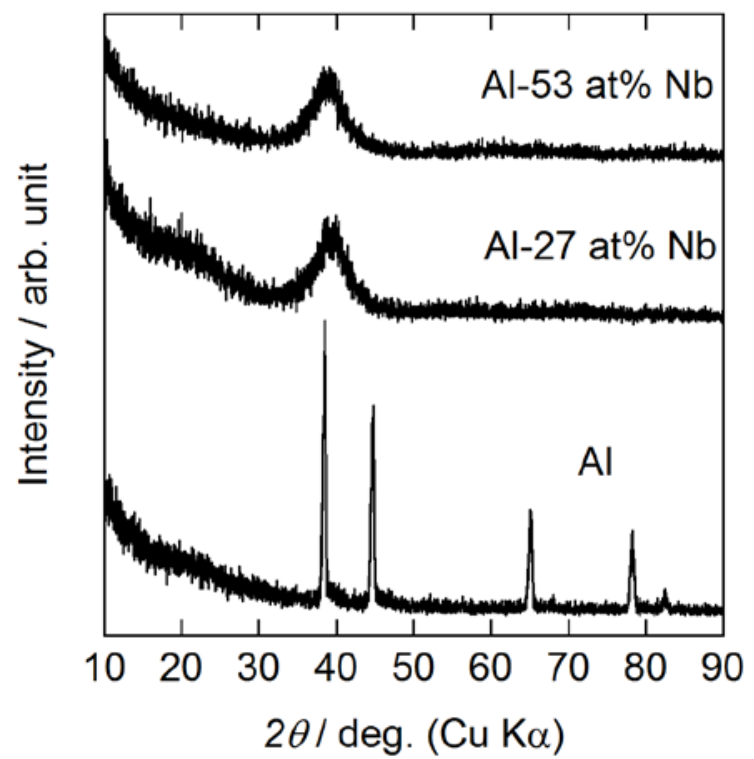

Figure 5 X-ray diffraction patterns of aluminum, $\mathrm{Al}-27 \mathrm{at} \% \mathrm{Nb}$ and $\mathrm{Al}-53 \mathrm{at} \% \mathrm{Nb}$ films deposited at $0^{\circ}$ on glass substrate.

The composition-dependent morphology of the deposits may be evolved by modified surface diffusivity of adatoms. Although the quantitative understanding is the subject of further study, the introduction of niobium should reduce the high diffusivity of aluminum adatoms. The formation of metastable amorphous alloy phase by the addition of niobium may be one of the evidences of the reduced surface diffusivity of adatoms. Limited surface diffusivity during deposition forces adatoms to locate metastable sites, impeding the formation of thermodynamically stable crystalline phase, such as $\mathrm{Al}_{3} \mathrm{Nb}$ intermetallic compound and fcc aluminum phase. For the $\mathrm{Al}-20 \mathrm{at} \% \mathrm{Nb}$, however, the surface diffusion to shadowing region may occur, such that widening of pillars and narrowing gaps between pillars occur after longer deposition.

\subsection{Influence of deposition angle}

Figure 6 shows the surface and cross-sectional SEM images of Al-Nb alloy films deposited at three different angles on the concave cell substrate with a cell size of 300-400 nm. Marked change in column morphology occurs with deposition angle. A unique nanoplate film is formed at a deposition angle of $110^{\circ}$ (Fig. 6c). The width and thickness of each plate are 500-700 nm and $200 \mathrm{~nm}$, respectively, with the former being roughly twice the cell size of 
substrate. Obvious gaps $(\sim 100 \mathrm{~nm})$ are present between neighboring nanoplates and the plate-to-plate distance is similar to the cell size of substrate $(\sim 400 \mathrm{~nm})$. From the nanoplate array dimension, it is likely that nanoplates develop based on the cell structure of the substrate. From cross-section image (Fig. 6(f)), no obvious change in columns thickness is found along the distance from the substrate, as in the case of Fig. 4(f).
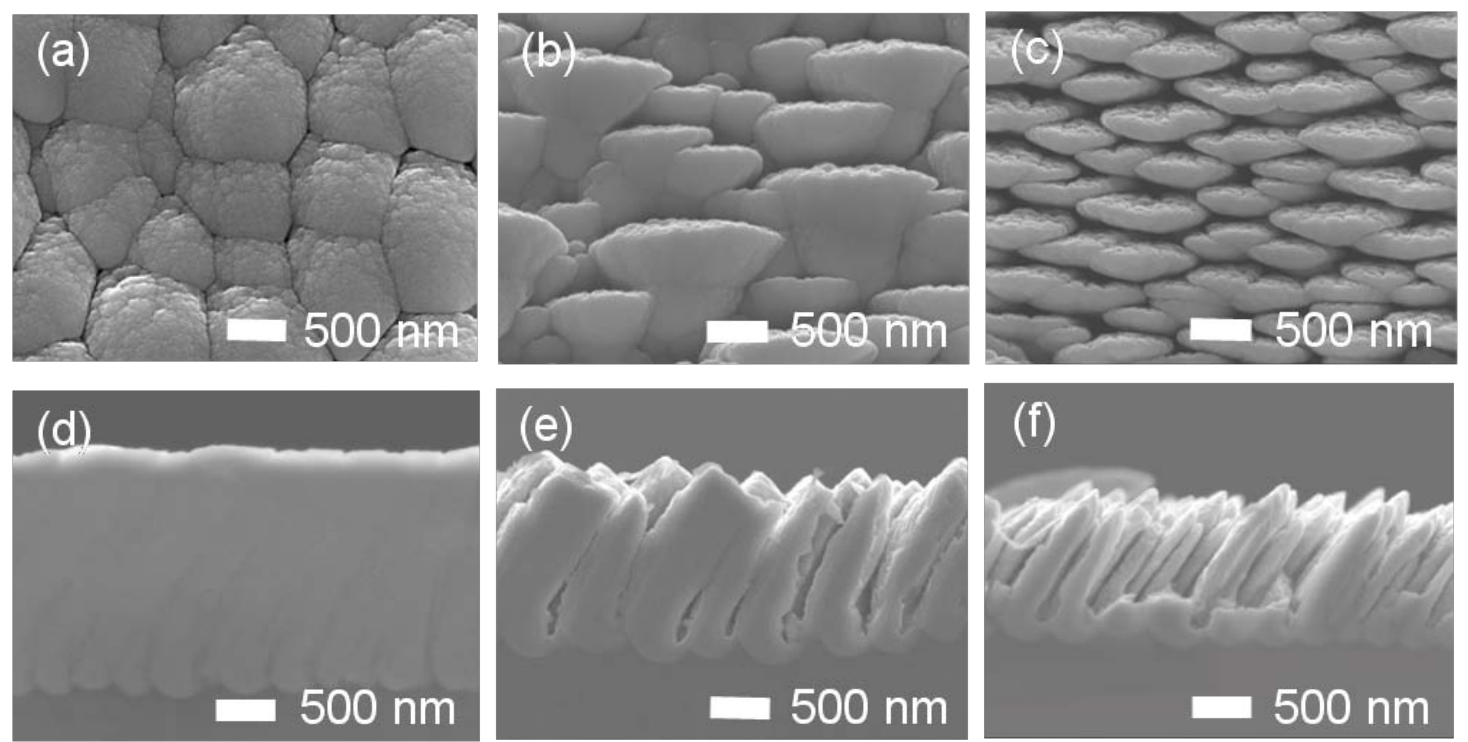

Figure 6 Scanning electron micrographs of surfaces and cross-sections of Al-(47, 43 and 36) at\% $\mathrm{Nb}$ deposited at several deposition angles of (a, d) $70^{\circ}$, (b, e) $85^{\circ}$ and (c, f) $110^{\circ}$ on textured substrates for $5.4 \mathrm{ks}$.

At a deposition angle of $70^{\circ}$, a round pillar film develops with no obvious gaps between pillars (Figs. 6(a) and 6(d)). Since the films deposited at $110^{\circ}$ are formed on the backside of the specimens with a deposition angle of $70^{\circ}$, the significant influence of the deposition angle is obvious. When the deposition angle increases to $85^{\circ}$, the column shape changes to triangular nanoprism. Small gaps are present between columns deposited at $85^{\circ}$, but gaps are filled partly as seen in cross-sectional SEM images (Fig. 6(e)). In addition to pillar shape, the width of columns decreases with an increase in deposition angle. As a consequence, gaps between columns enlarged at higher deposition angles.

The evolution of angle-dependent morphologies should be associated with a shadowing effect generated by a substrate texture. Figure 7 shows schematic illustrations of the deposits obtained at different deposition angles. Fig. 7(a) reveals the cell structure of substrate. When the deposition angle is high $\left(110^{\circ}\right)$, deposition should occur only on the cell boundaries that are normal to the incident direction of depositing atoms, since the cell boundary is ridge. Thus, plate-like deposits are obtained as shown in Fig. 7(b). Even though the deposition angle is 
greater than $90^{\circ}$, the thickness of the alloy film is $\sim 0.6$ that deposited at $70^{\circ}$. The relatively thick film deposition at $110^{\circ}$ indicates that there are relatively high incident atoms with random orientation. When the deposition angle is reduced to $85^{\circ}$, the deposition region is slightly extended to the incident flux side of the each cell (Fig. 7(c)), forming triangle nanoprism pillars. Further reduction of the deposition angle to $70^{\circ}$ limits the shadow regions, forming round deposits around the cell boundaries that are normal to the incident flux(Fig. 7(d)). Little gaps are also developed between pillars. Although regular hexagonal cell structure of substrate is drawn in Fig. 7(a), the substrates used contain irregular shaped cells with cell boundaries of two or three cells being approximately in line (Fig. 1(b)), on which one pillar of either plate, triangular prism or round shape should be formed.

(a)

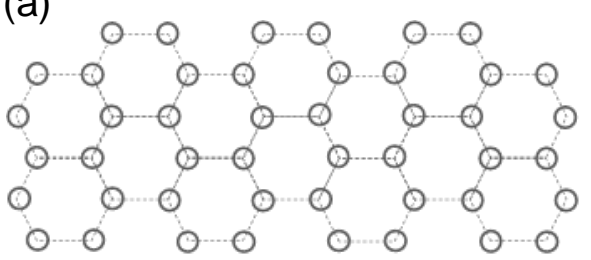

(b)

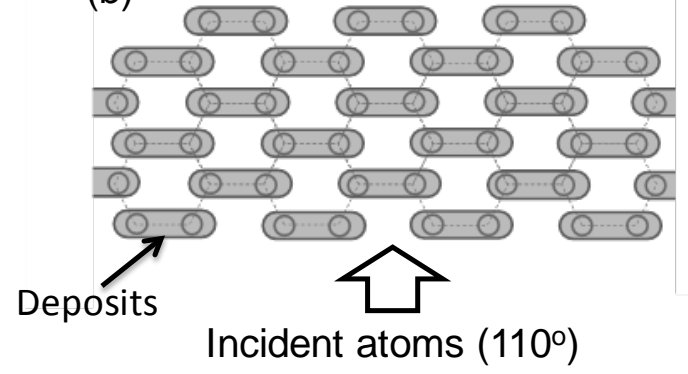

(c)

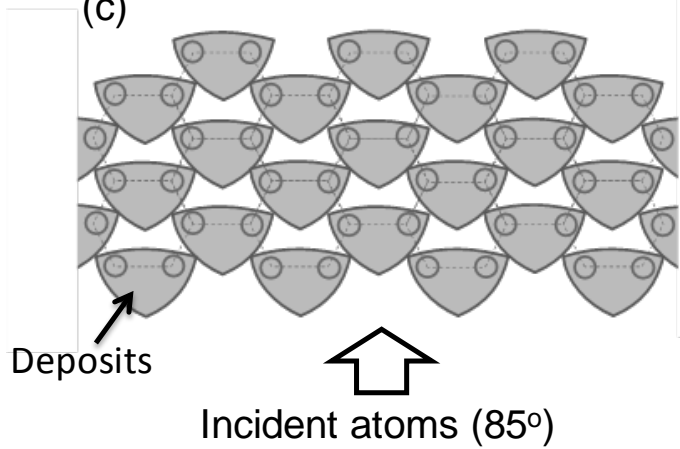

(d)

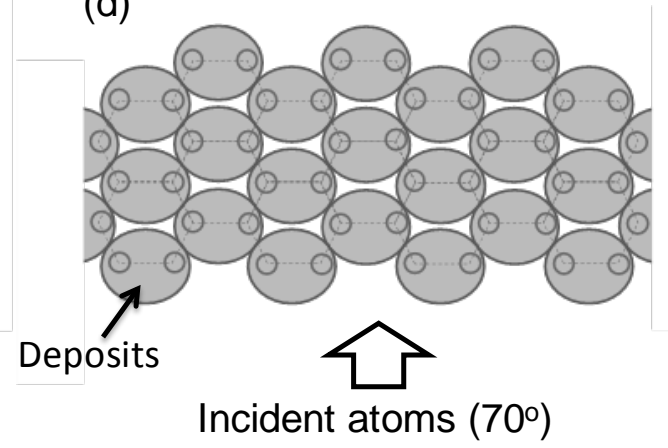

Figure 7 Schematic illustrations showing the correlation between substrate cell structure and deposits at different deposition angles. (a) substrate cell structure with triple cell boundaries depicted as circles, (b) nanoplates deposited at $110^{\circ}$, (c) triangle nanoprisms deposited at $85^{\circ}$ and (d) round pillars deposited at $70^{\circ}$.

\subsection{Formation of anodic oxide films on Al-Nb nanopillars}

Figure 8 shows the voltage-time responses of the Al-Nb nanopillar films deposited at different angles during anodizing at a constant current density of $10 \mathrm{~A} \mathrm{~m}^{-2}$ in $0.1 \mathrm{~mol} \mathrm{dm}^{-3}$ 
ammonium pentaborate electrolyte. The response of the flat $\mathrm{Al}-53$ at\% $\mathrm{Nb}$ film is also shown for comparison. It is known that the anodic films on Al-Nb binary alloys develop at a high current efficiency close to $100 \%$ [30]. In this case, the slope, $d V / d t$, at a current density, $i$, is derived from the following equation,

$$
\frac{\mathrm{d} V}{\mathrm{~d} t}=\frac{i E M}{z F \rho}
$$

in which $E$ is the field strength in growing anodic oxide, $M$ is the molecular weight of oxide formed, $z$ is the number of electrons and $\rho$ is the density of oxide. Thus, under the uniform film growth at a high current efficiency, the slope is unchanged. In other words, the cell voltage increases linearly with anodizing time. In fact, the cell voltage rises linearly for the flat Al-53 at\% $\mathrm{Nb}$ with a slope of $0.32 \mathrm{~V} \mathrm{~s}^{-1}$. The slope is in-between those of electropolished aluminum $\left(0.42 \mathrm{~V} \mathrm{~s}^{-1}\right)$ and sputter-deposited flat niobium $\left(0.26 \mathrm{~V} \mathrm{~s}^{-1}\right)$. It has been reported that growth parameters, such as slope, field strength and Pilling-Bedworth ratio, of anodic films on binary valve metal alloys are compositional average of those on alloy constituting elements, if the anodic oxides formed are amorphous as in the case of anodic aluminum oxide and niobium oxide [31]. From the slope during anodizing aluminum and niobium, the slope for flat Al-53 at\% $\mathrm{Nb}$ is predicted to be $0.33 \mathrm{~V} \mathrm{~s}^{-1}$ from its composition, which is in agreement with the observed slope.

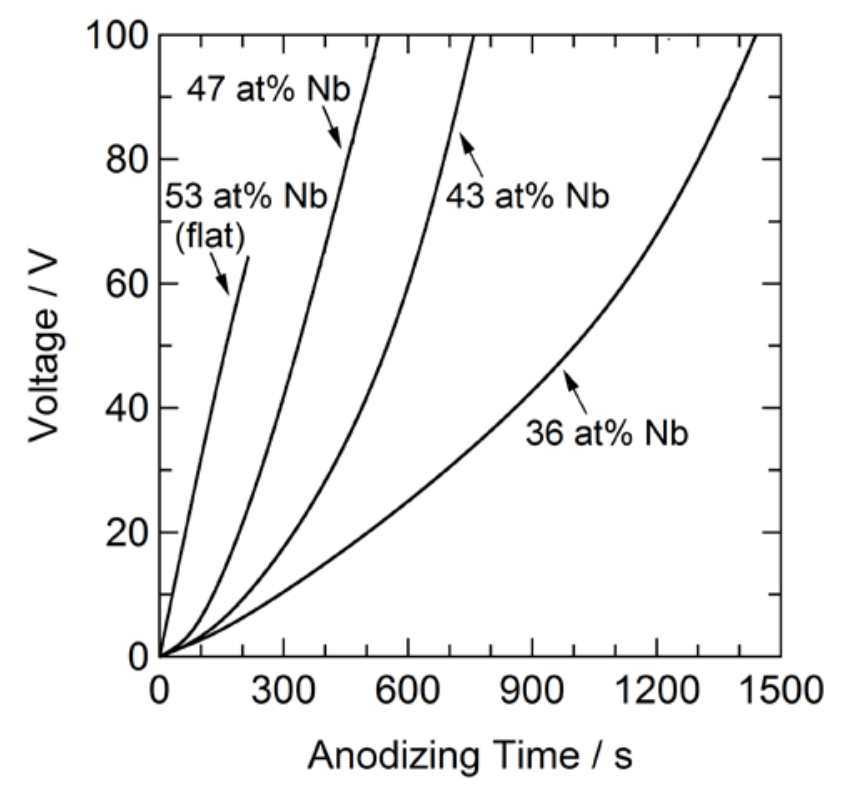

Figure 8 Voltage-time responses of the Al-(47, 43 and 36) at\% $\mathrm{Nb}$ nanopillar films deposited at different deposition angles of 70,85 and $110^{\circ}$ during anodizing at a constant current density of $10 \mathrm{~A} \mathrm{~m}^{-2}$ in $0.1 \mathrm{~mol} \mathrm{dm}^{-3}$ ammonium pentaborate electrolyte at $293 \mathrm{~K}$. The response of flat $\mathrm{Al}-53 \mathrm{at} \% \mathrm{Nb}$ film is also shown for comparison. 
For the specimens deposited at oblique angles, the initial slope is significantly lower than that of flat $\mathrm{Al}-53 \mathrm{at} \% \mathrm{Nb}$, even though higher slopes are expected due to their lower niobium contents. The reduced slope is associated with the increased surface area, since a constant current density of $10 \mathrm{~A} \mathrm{~m}^{-2}$ has been set with respect to the geometrical surface area. This means that the real current density becomes lower than the apparent current density. The lower slope at a lower current density is obvious from the equation (1). The lower initial slope at a higher deposition angle indicates the higher surface area of the films deposited at a higher deposition angle.

Although the initial slopes for the films deposited at oblique angles are lower than that of the flat $\mathrm{Al}-53 \mathrm{at} \% \mathrm{Nb}$, the slopes increase with anodizing time. For the films deposited at 70 and $85^{\circ}$, the slopes become similar to that for the flat $\mathrm{Al}-53 \mathrm{at} \% \mathrm{Nb}$ at high formation voltages close to $50 \mathrm{~V}$. The increased slope is associated with the reduced surface area, and the gaps between columns should be almost filled with oxide at high voltages. In contrast, the slope for the film deposited at $110^{\circ}$ is still markedly lower than that of flat $\mathrm{Al}-53$ at\% $\mathrm{Nb}$ even at voltages close to $50 \mathrm{~V}$.

The Pilling-Bedworth ratio (PBR), that is, the ratio of the thickness of anodic oxide film to the thickness of metallic substrate consumed by anodizing, is 1.65 for aluminum and 2.5 for niobium [32]. For Al-Nb alloys, the PBR should be in the range of 1.65 and 2.5, with the value increasing with niobium content. Since the PBRs for Al-Nb alloys are larger than unity, the gaps between columns become smaller during anodizing and will be filled at high formation voltages. The similar slopes for the specimens deposited at 70 and $85^{\circ}$ to that for the flat Al-53 at\% $\mathrm{Nb}$, suggest that gaps between nanopillars are almost completely filled with oxide. In contrast, the gaps should be still open at voltages close to $50 \mathrm{~V}$ such that the slope is lower than that for the flat $\mathrm{Al}-53 \mathrm{at} \% \mathrm{Nb}$.

The increased surface area and enhanced capacitance by porous nanocolumnar structure of the deposits have been further examined quantitatively by ac impedance measurements. Bode plots of the specimens deposited at $110^{\circ}$ and anodized at several formation voltages (Fig. 9) reveal linear change in impedance with a slope close to -1 and phase shift to $-90^{\circ}$ below $100 \mathrm{~Hz}-1 \mathrm{kHz}$, which are characteristic behavior of dielectric materials. Constant impedance at high frequency corresponds to the resistance of electrolyte. The increased impedance at each frequency below $1 \mathrm{kHz}$ discloses the reduction of capacitance mainly due to increased thickness of the anodic film. Experimental impedance spectra have been fitted with an equivalent circuit model, shown in Fig. 9, containing constant phase element (CPE) to compensate roughness of deposited film. The impedance of a CPE, $Z$, is given by 


$$
Z=\frac{1}{A(j \omega)^{n}}
$$

in which $j$ is the square root of negative one, $\varpi$ is the angular frequency of the applied ac signal, and $A$ and $n$ are determinable parameters [33]. The $n$ value in this work was $0.95 \sim 0.99$, being close to 1 . Thus, a CPE behaves like a capacitor.

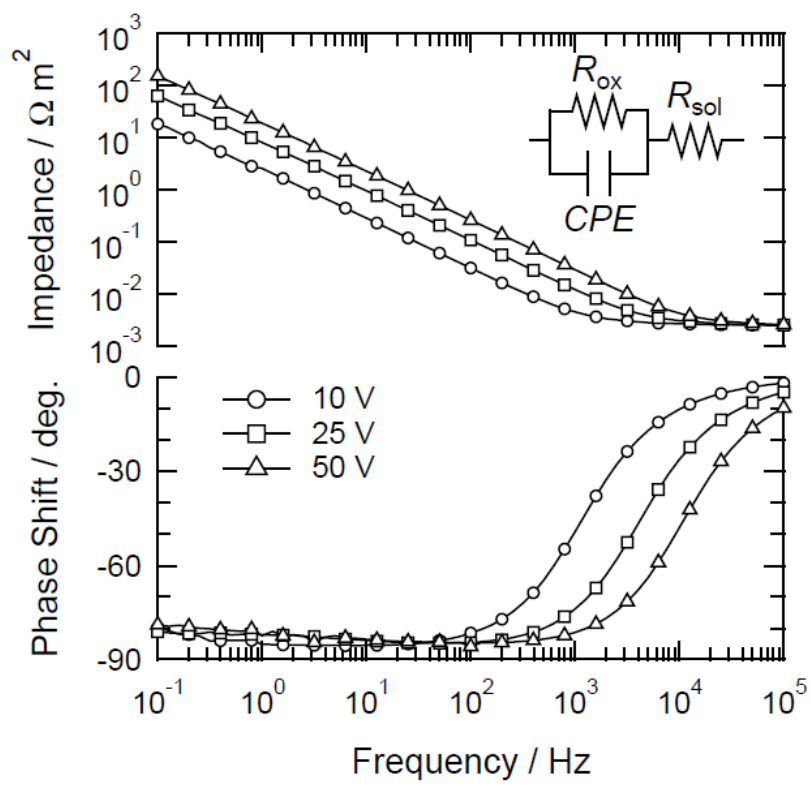

Figure 9 Bode diagrams of the Al-36 at\% $\mathrm{Nb}$ nanoplate films anodized at 10, 25 and $50 \mathrm{~V}$ in $0.1 \mathrm{~mol} \mathrm{dm}^{-3}$ ammonium pentaborate electrolyte at $293 \mathrm{~K}$ for $600 \mathrm{~s}$, following constant current anodizing at $10 \mathrm{~A} \mathrm{~m}^{-2}$ to the respective formation voltages.

The capacitance, $C$, of anodic oxide films is inverse proportional to the film thickness, $d$, as in the following equation,

$$
C=\frac{\varepsilon_{0} \varepsilon_{o X} S}{d}
$$

in which, $\varepsilon_{0}$ is permittivity of vacuum, $\varepsilon_{\mathrm{ox}}$ is the specific permittivity of anodic oxide and $S$ is the surface area. Thus, the reciprocal of capacitance of the anodic films formed on the Al-36 at\% $\mathrm{Nb}$ nanoplate films, as well as those on electropolished aluminum and flat $\mathrm{Al}-53 \mathrm{at} \% \mathrm{Nb}$ film, is plotted as a function of formation voltage (Fig. 10). Since the film thickness changes linearly with the formation voltage, the reciprocal capacitance increases linearly with the formation voltage for flat films. The capacitance of the anodic film formed on the flat Al-53 at\% Nb film is larger than that on electropolished aluminum at each formation voltage, due to enhanced permittivity by the incorporation of niobium species into the anodic alumina film. Obviously, the anodic films formed on the $\mathrm{Al}-36$ at\% $\mathrm{Nb}$ nanoplate film reveal largely increased 
capacitance, compared with those on the flat $\mathrm{Al}-53 \mathrm{at} \% \mathrm{Nb}$ film. Assuming an additive property of the capacitance of the anodic oxide films formed on flat $\mathrm{Al}-\mathrm{Nb}$ alloys, the reciprocal capacitances of the anodic oxide films formed on the flat $\mathrm{Al}-36 \mathrm{at} \% \mathrm{Nb}$ film are predicted as in Fig. 10. Since the anodic films of the same composition and thickness should be formed on flat and nanoplate $\mathrm{Al}-36 \mathrm{at} \% \mathrm{Nb}$ films, the increased rate of the capacitance of the anodic films on the nanoplate alloy film, relative to the respective flat film, corresponds to the increased rate of surface area. Using the predicted capacitances of the anodic oxide films formed on the flat Al-36 at\% $\mathrm{Nb}$ alloy film, the surface areas of the anodic films formed on the nanoplate film should increase 11, 7 and 6 times that on respective flat ones at 10, 25 and $50 \mathrm{~V}$, respectively. It is likely that further increased surface area and capacitance can be readily obtained by prolonged deposition.

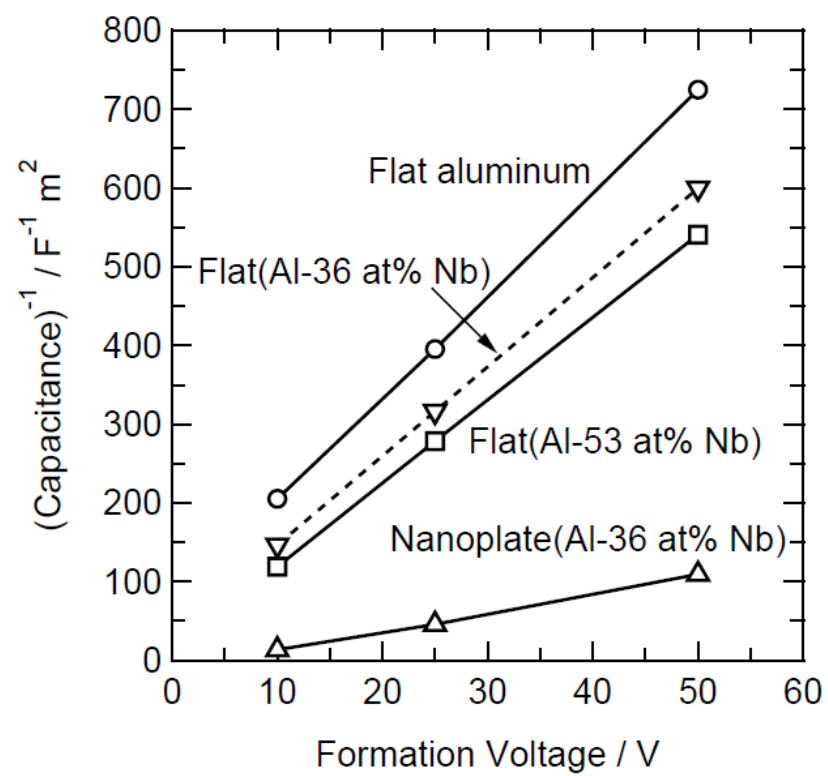

Figure 10 The formation voltage dependence of the reciprocal of capacitance of the anodic oxide films, formed on Al-36 at\% Nb nanoplate film $(\triangle)$ and on flat electropolished aluminum (O)and Al-53 at\% $\mathrm{Nb}(\square)$. The estimated values for the flat Al-36 at\% Nb $(\nabla)$ film is also revealed.

\section{Conclusions}

1) Porous nanopillar films of $\mathrm{Al}-\mathrm{Nb}$ alloys can be fabricated by oblique angle magnetron sputtering on a textured substrate with a regular concave cell structure. The relatively large cell size of substrate, $300-400 \mathrm{~nm}$, is necessary to form isolated nanopillar films. 
2) Nanopillar morphology is dependent upon the alloy composition and deposition angle; nanopillars with the shape of nanohorns, triangle nanoprisms and nanoplates are fabricated, with the nanoplates having wider gaps between pillars.

3) Due to increased surface area and increased permittivity by incorporation of niobium species, the capacitance of anodic oxide films formed on the nanoplate films is highly enhanced by more than 10 times in comparison with that on flat aluminum.

\section{Acknowledgments}

The present work was supported in part by Grants-in-Aid for Scientific Research (A) No. 19206077 and for Exploratory Research, No.21656180 from the Japan Society for the Promotion of Science, and also by the Global COE Program (Project No. B01: Catalysis as the Basis for Innovation in Materials Science) from the Ministry of Education, Culture, Sports, Science and Technology, Japan.

\section{References}

[1] Hawkeye M M and Brett M J 2007 Glancing angle deposition: Fabrication, properties, and applications of micro- and nanostructured thin films J. Vac. Sci. Technol., A 25 1317-35

[2] Tsujii K, Yamamoto T, Onda T and Shibuichi S 1997 Super oil-repellent surfaces Angew. Chem., Int. Ed. Engl. 36 1011-2

[3] Steele J J and Brett M J 2007 Nanostructure engineering in porous columnar thin films: recent advances J. Mater. Sci. Mater. Elect. 18 367-79

[4] Zhou C M and Gall D 2007 Competitive growth of Ta nanopillars during glancing angle deposition: Effect of surface diffusion J. Vac. Sci. Technol., A 25 312-8

[5] Zhou C M and Gall D 2006 The structure of Ta nanopillars grown by glancing angle deposition Thin Solid Films 515 1223-7

[6] Malac M and Egerton R F 2001 Observations of the microscopic growth mechanism of pillars and helices formed by glancing-angle thin-film deposition J. Vac. Sci. Technol., A 19 158-66

[7] Malac M, Egerton R F, Brett M J and Dick B 1999 Fabrication of submicrometer regular arrays of pillars and helices J. Vac. Sci. Technol. B 17 2671-4

[8] Robbie K, Shafai C and Brett M J 1999 Thin films with nanometer-scale pillar microstructure $J$. Mater. Res. 14 3158-63

[9] Dick B, Brett M J and Smy T 2003 Controlled growth of periodic pillars by glancing angle deposition J. Vac. Sci. Technol. B 21 23-8

[10] Robbie K and Brett M J 1997 Sculptured thin films and glancing angle deposition: Growth 
mechanics and applications J. Vac. Sci. Technol. A 15 1460-5

[11] Suzuki M, Ito T and Taga Y 2001 Photocatalysis of sculptured thin films of $\mathrm{TiO}_{2}$ Appl. Phys. Lett. 78 3968-70

[12] Lintymer J, Martin N, Chappe J M, Delobelle P and Takadoum J 2004 Influence of zigzag microstructure on mechanical and electrical properties of chromium multilayered thin films Surf. Coat. Technol. 180-81 26-32

[13] Messier R, Venugopal V C and Sunal P D 2000 Origin and evolution of sculptured thin films $J$. Vac. Sci. Technol., A 18 1538-45

[14] Toader O and John S 2001 Proposed square spiral microfabrication architecture for large three-dimensional photonic band gap crystals Science 292 1133-5

[15] Kennedy S R, Brett M J, Toader O and John S 2002 Fabrication of tetragonal square spiral photonic crystals Nano Lett. 2 59-62

[16] Wang J, Huang H C, Kesapragada S V and Gall D 2005 Growth of Y-shaped nanorods through physical vapor deposition Nano Lett. 5 2505-8

[17] Watanabe K, Sakairi M, Takahashi H, Takahiro K, Nagata S and Hirai S 2001 Anodizing of aluminum coated with silicon oxide by a sol-gel method J. Electrochem. Soc. 148 B473-B81

[18] Watanabe K, Sakairi M, Takahashi H, Takahiro K, Nagata S and Hirai S 2001 Formation of composite oxide films on aluminum by sol-gel coating and anodizing - For the development of high performance aluminum electrolytic capacitors Elechem. 69 407-13

[19] Watanabe K, Sakairi M, Takahashi H, Takahiro K, Nagata S and Hirai S 1999 Anodizing of aluminum coated with zirconium oxide by a sol-gel process I. Effect of heat treatment on the formation of the anodic oxide film Elechem. 67 1243-8

[20] Watanabe K, Sakairi M, Takahashi H, Hirai S and Yamaguchi S 1999 Formation of Al-Zr composite oxide films on aluminum by sol-gel coating and anodizing J. Electroanal. Chem. 473 $250-5$

[21] Takahashi H, Kamada H, Sakairi M, Takahiro K, Nagata S and Yamaguchi S 1998 Dielectric Material Integration for Microelectronics, ed W D Brown, et al. (Pennington: Electrochemical Society Inc) pp 253-62

[22] Koyama S, Kikuchi T, Sakairi M, Takahashi H and Nagata S $2007 \mathrm{Nb}_{2} \mathrm{O}_{5}$ deposition on aluminum from $\mathrm{NbCl}_{5}$-used sol and anodizing of $\mathrm{Nb}_{2} \mathrm{O}_{5}$-coated $\mathrm{Al}$ Elechem. 75 573-5

[23] Masuda H and Fukuda K 1995 Ordered Metal Nanohole Arrays Made by a 2-Step Replication of Honeycomb Structures of Anodic Alumina Science 268 1466-8

[24] Thompson G E 1997 Porous anodic alumina: Fabrication, characterization and applications Thin Solid Films 297 192-201

[25] Dick B, Brett M J and Smy T 2003 Investigation of substrate rotation at glancing-incidence on thin-film morphology J. Vac. Sci. Technol. B 21 2569-75 
[26] Ebihara K, Takahashi H and Nagayama M 1983 Structure and density of anodic oxide films formed on aluminum in oxalic acid solutions J. Surf. FInish. Soc. Jpn. 35 548-53

[27] Li A P, Muller F, Birner A, Nielsch K and Gosele U 1998 Hexagonal pore arrays with a 50-420 $\mathrm{nm}$ interpore distance formed by self-organization in anodic alumina J. Appl. Phys. 84 6023-6

[28] Tait R N, Smy T and Brett M J 1993 Modelling and characterization of columnar growth in evaporated films Thin Solid Films 226196

[29] Habazaki H, Shimizu K, Skeldon P, Thompson G E and Wood G C 1997 Formation of amorphous anodic oxide films of controlled composition on aluminium alloys Thin Solid Films 300 131-7

[30] Habazaki H, Skeldon P, Thompson G E, Wood G C and Shimizu K 1996 Anodizing of multilayer alloy films formed by sputter-deposition of valve metals Phil. Mag. B 73 297-308

[31] Habazaki H, Shimizu K, Skeldon P, Thompson G E and Wood G C 1997 Inter-relationships between ionic transport and composition in amorphous anodic oxides Proc. R. Soc. Lond. A 453 1593-609

[32] Pringle J P S 1980 The anodic oxidation of superimposed metallic layers: theory Electrochim. Acta 25 1423-37

[33] Huang V M-W, Vivier V, Orazem M E, Pébère N and Tribollet B 2007 The Apparent Constant-Phase-Element Behavior of a Disk Electrode with Faradaic Reactions J. Electrochem. Soc. 154 C99-C107 